\title{
Patients with learning disability at Kneesworth House Hospital
}

\section{The first five years}

\author{
Deborah Brooke
}

\begin{abstract}
This paper reports a retrospective case note study of all patients with learning discability and challenging behaviour admitted to Kneesworth House Hospltal between 1986 and 1991 ( $n=70)$, describing their demographic and clinical characteristics. The subjects had high levels of poychiatic morbidity, in addition to leaming discablitity. Patients whose stay was relatively short, or who were discharged to community placements, were not able to be differentiated on clinical grounds, suggesting that the provision of local facilities determined the length of the admission. There is a need for more regional and sub-regional services for this group with multiple long-ferm problems.
\end{abstract}

Kneesworth House Hospital in Hertfordshire is a private hospital run by Partnerships in Care. From 1986, patients with learning disability and challenging behaviour were admitted to a semisecure in-patient unit. This was housed in modern premises, with communal living and dining areas. During the day, the bedrooms were closed to patients, who were offered education. physical activity, occupational therapy and trips to the local community. The unit ran a behaviourally-oriented treatment programme, with residents progressing through levels of decreasing monitoring. In addition to weekly ward rounds, each patient was fully reviewed every three months at a multi-disciplinary meeting with the purchasers.

In 1992, a new unit (St John's, Diss) opened, offering assessment and treatment services and facilities for longer-term rehabilitation. This is a retrospective case note study, carried out on the patients with learning disability treated at Kneesworth House during the period prior to the opening of St John's. It describes the clinical characteristics of these patients and examines their progress during their stay, in terms of drugs prescribed and discharge destinations.

\section{The study}

The case notes of all those admitted to the unit were examined. Data were abstracted from the notes using a structured schedule, which recorded information about demographic and clinical characteristics, family and professional involvement, drugs prescribed and behavioural problems. Psychiatric diagnoses were also recorded from the notes. For those subjects who had stayed longer than 12 months, major tranquilliser dosage was recorded at threemonthly intervals. Neuroleptic dosages were recorded as chlorpromazine equivalents (Johnson \& Wright, 1990).

Data were analysed using chi-squared and regression in the Epi-Info statistical package.

\section{Findings}

\section{Demographic and clinical details}

Seventy people had been admitted to the unit during the five-year period 1986-1991, and a complete set of notes was available on them all. Fifty-two (74\%) were male (average age 24 , range 16-41 years) and 18 were female, (average age 25 , range 16-39). Twenty-seven (39\%) were informal admissions; 34 (49\%) were admitted under sections 2 and 3 of the Mental Health Act 1983 and nine (13\%) were admitted under other sections. Sixty-seven subjects (96\%) had never married.

Thirty-seven subjects (53\%) had mild to moderate learning disability (1Q 50-75) and $28(40 \%)$ had severe learning disability $(I Q<50)$. This information was not available for three subjects, and two had IQ's over 75. (For three cases, the aetiology of the learning difficulty was recorded in the notes - one subject each had Fraglle $X$ syndrome, Down's syndrome and Prader-Willi syndrome.) Seventeen subjects (24\%) had significant difficulties in speech and communicating, the rest had minimal or no difficulties in this area. Nine subjects (13\%) had a physical disability and $18(25 \%)$ had epilepsy, half of whom suffered from three or more fits per year.

Psychiatric illness was common. Thirty-two people $(45 \%)$ had one psychiatric illness; eight (11\%) had two. Nineteen subjects $(27 \%)$ had a 
psychosis, of whom half were atypical: the next most frequent diagnoses were autistic traits, including Asperger's syndrome, in nine subjects $(13 \%)$ and autism in six $(8 \%)$. A further eight (11\%) had an organic diagnosis, such as brain damage following status epilepticus. Neurotic disorders were recorded in only three cases. The diagnosis of personality disorder was recorded if it was written in the notes, or if there was clear evidence clinically of longstanding difficulties in multiple areas of personality functioning. It was not used for those with organic brain syndromes, or those with severe learning disability. Fourteen subjects $(20 \%)$ were found to have a personality disorder, most commonly with antisocial or emotionally unstable features. Polypharmacy was common. Some reduction in neuroleptics and mood-altering drugs was achieved. There was an increase in anti-epileptic agents due to the addition of carbamazepine to some drug regimes (see Table 1).

\section{Route of referral}

These patients had come from a variety of placements: 20 (29\%) from a long-stay ward, 14 $(20 \%)$ from a short-stay ward, $20(29 \%)$ from a community placement (including eight from their family), eight (11\%) from adolescent units and special schools and seven (10\%) from prison. One patient was on trial leave from a maximumsecurity hospital. Many admissions from shortstay wards and the community were 'crisis' admissions. The geographical distribution of purchasers (health authority and/or social services departments) is shown in Fig. 1.

South East and North East Thames were the two largest referring regions up until 1991. The usual request was for assessment, rehabilitation and advice on placement. A group of seven patients was admitted in 1986 because their long-stay psychiatric hospital was closing.

Table 1. Classes of drugs prescribed, $n=70(\%)^{\prime}$

\begin{tabular}{lll}
\hline Class of drug & At admission & $\begin{array}{l}\text { At discharge (or } \\
\text { study date If not } \\
\text { yet discharged) }\end{array}$ \\
\hline Neuroleptics & $54(77)$ & $50(71)$ \\
Anticholinergics & $30(43)$ & $27(39)$ \\
Anticonvulsants & $20(29)$ & $30(43)$ \\
Minor tranquillisers & $14(20)$ & $10(14)$ \\
Lithlum & $9(13)$ & $9(13)$ \\
Antidepressants & $5(7)$ & $3(4)$ \\
Others & $15(21)$ & $30(43)$ \\
None & $7(10)$ & $6(9)$ \\
\hline
\end{tabular}

1. Subjects could be prescribed more than one class of drug.

\section{Contact with local services}

The basis for liaison with local services was the three-month review meetings. Of the 70 admissions, 41 (59\%) had regular, sustained involvement with both significant others and professionals involved in their case; 17 (24\%) had contact only with professionals. Staff at Kneesworth House regarded their contact with local services as satisfactory in the majority of cases: sometimes it was excellent. Eleven patients (16\%) had contact only with family members or friends. Of these, most had no effective 'community links' with local services before they transferred to Kneesworth House. One case had no outside involvement during admission. In the majority of cases where good family ties existed, these were largely maintained.

\section{Duration of stay and discharge data}

For the whole sample of 70 , the median duration of stay was 15 months. Thirty-four subjects were in-patients at the time of the study. The average stay in this group was 20.1 months (range 3-62 months, s.d. 15.9). Examination of factors (such as gender, age, mental and physical disorders. IQ and outside involvement) that might discriminate between those who stayed longer than the median did not reveal any significant differences between the two groups. There was a borderline trend $(P=0.06)$ for those with the lowest IQ to stay longer. Forty-two patients $(60 \%)$ stayed longer than 12 months. Each of the 42 subjects were allocated up to three problem behaviours on the basis of the notes at admission (see Table 2 for frequencies); 40 of the 42 had two or more behavioural problems. In this group, major tranquilliser dosage was recorded at threemonthly intervals, to examine any changes during admission. The regression line for dosage showed no trends over time.

Thirty-five people had been discharged and one had died while an in-patient. The average length of stay for those who had been discharged was 23.8 months (range 1-65 months, s.d. 17.2). Twenty-four went to a community placement, including three who went to their own home, 10 went to a hospital-based, long-stay rehabilitation facility and one went to a high-dependency placement. Examination of any factors (such as IQ. age, gender, psychiatric diagnosis, personality disorder, epilepsy, outside involvement or physical disability) that might have differentiated the group discharged to a community placement did not show any significant differences, except that those with a physical disability were significantly more likely to go to a community placement: of the nine with a physical disability, six $(67 \%)$ went to a community placement compared to $18(30 \%)$ of those without a physical 


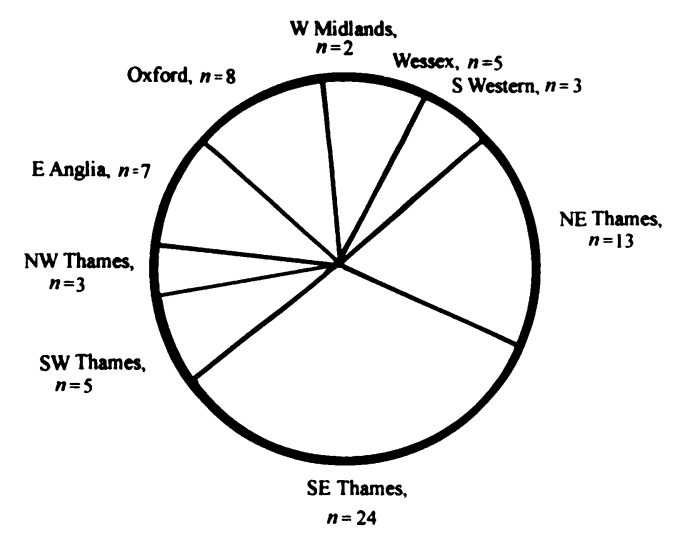

Figure 1. Funding bodies by region, 1986-1991 $(n=70)$.

disability $(0.02>P>0.01)$. The dozen patients who stayed for $\mathbf{4 0}$ months or longer were a heterogeneous group ranging from moderate to severely disabled with other problems such as communication difficulties and suspected autism. Some patients had committed offences and one had been treated in a special hospital. A common factor for the majority of them was that they had experienced very long periods of institutional care. They had often left behind them a reputation within local services that could have hindered their integration. Each of them posed substantial management and placement difficulties, and thus they were difficult to reintegrate locally.

\section{Comment}

\section{Limitations of the study}

This study is a retrospective case note study, and so its conclusions depend on the accuracy of the recorded data. The subjects were highly selected and are not representative of people generally, with learning disability and behavioural distur-

Table 2. Frequency of challenging behaviours on admission among the 42 subjects who stayed longer than 12 months'

\begin{tabular}{ll}
\hline Behoviour & Frequency \\
\hline Injury to others & 41 \\
Property damage & 15 \\
Inappropriate sexual behaviour & 14 \\
Other (including theft and arson) & 11 \\
Self-injury & 10 \\
Absconding & 7 \\
Inappropriate urination and/or defaecation 6
\end{tabular}

1. Up to three challenging behaviours were reported per subject. bance. They came from a wide geographical area and their admission to semi-secure provision in the private sector may reflect a lack of local facilities, rather than clinical feature of their case. A significant minority had tenuous or minimal links with their families and local services prior to admission to Kneesworth House.

However, this selectivity does give this group of patients a particular importance. They are patients for whom local services were too limited. or unavailable. Frameworks for their management within current philosophies of communitybased care have yet to be found in many areas.

\section{Methodological issues}

The neuroleptic dosages showed no change over time. The literature emphasises the need to monitor prescribing in patients with learning disability and behavioural disturbance (Manchester, 1993), but this outcome measure can be criticised for being too pragmatic and blunt in this very damaged population. There is a need to develop instruments to measure subtle but significant improvements in functioning such as a longer attention span, improved language or the acquisition of skills. Efforts to differentiate on clinical criteria between those who were placed in the community or in institutional care, or between those who stayed for longer or shorter periods than the median of 15 months, did not demonstrate any significant differences. The sample was perhaps too small to show such differences, but it is the experience of the Kneesworth House staff that placements are determined by local facilities. Their long-stay patients are usually from areas where services for learning difficulties and challenging behaviours cannot meet the local need. Referral patterns change as local facilities are established.

\section{Implications for practice and service development}

This group was characterised by being placed outside local services. Those with good community links generally maintained them during their admission, and those without community ties on admission were more difficult to place. This case note review does not suggest that community ties were substantially weakened by their admission to Kneesworth House. Figure 1 shows that the purchasers for this early cohort of admissions were from the south of the UK. The hospital built-up relationships with these areas over the years to facilitate contact with local services.

The majority of these subjects were men, admitted under the Mental Health Act. Their 
average duration of stay was two years. The group have similar problems to another published series (Murphy et al, 1991), and the figure of $20 \%$ with a personality disorder in this hospitalised group accords with previous findings (Reid \& Ballinger, 1987). Nearly half suffered from psychiatric disorder in addition to learning difficulty. Depression and anxiety were under-represented compared to a general population prevalence of about 10\% (Meltzer et ah 1994), illustrating possible difficulties in diagnosing anxiety and depression in a group with communication problems. In addition to a range of severe psychiatric disorders, one-quarter of the group did not have significant contact with their family during their admission. Three came directly from a long-stay adolescent unit, having passed their sixteenth birthday. National Health Service provision for long-term mental illness, including learning disability and challenging behaviours, is inadequate (Coid, 1991). Subjects had multiple behavioural problems. It is precisely this group of patients for whom there is a lack of local assessment and treatment facilities. These experiences of rejection reduce selfesteem, increase maladaptive behaviours such as self-harm and contribute further to the alienation of these patients.

\section{Acknowledgements}

Thanks are due to all at Kneesworth House and St George's Hospital who facilitated this study and who contributed greatly to the discussion.
Dette Lynch, formerly of the Statistics Department, Mental Health Sciences, St George's Hospital Medical School, performed much of the statistical analysis.

\section{References}

CoID, J. (1991) 'Difficult to place' psychiatric patients. British Medical Journal, 302, 603-604.

JohnSON. D. \& WRIGHT, N. (1990) Drug prescribing for schizophrenic out-patients on depot injections. Repeat surveys over 18 years. British Joumal of Psychiatry. 156. 827-834.

MANCHESTER, D. (1993) Neuroleptics, learning disability and the community: some history and mystery. British Medical Journal, 307, 184-187.

MELTZER, H., GILL, B. \& PETTCREW, M. (1994) OPCS Surveys of Psychiatric Morbidity in Great Britain (Bulletin number 1). London: Office of Population Censuses and Surveys.

MURPHY, G., Holland, A., Fowler, P., et al (1991) A service option for people with mild mental handicaps and challenging behaviour or psychlatric problems. 1: Philosophy, service and service users. Mental Handicap Research, 4, 41-66.

REID, A. \& BALUNGER, B. (1987) Personality disorder in mental handicap. Psychological Medicine, 17, 983-987.

Deborah Brooke, formerly Senior Registrar, Division of Psychiatry of Disability. St George's Hospital Medical School, Cranmer Terrace, London SW17 ORE

Correspondence: Dr D. Brooke. Consultant Forensic Psychiatrist, The Bracton Centre, Bexley Hospital, Old Bexley Lane, Bexley, Kent DA5 2BW 